\title{
El lugar de la utopía en la historia
}

\author{
The place of utopia in history \\ Iván Fernando Rodrigo-Mendizábal \\ Universidad Andina Simón Bolívar, Quito, Ecuador \\ Contacto: ivan.mendizabal@uasb.edu.ec \\ https://orcid.org/0000-0001-6394-4752
}

\begin{abstract}
Resumen
El artículo examina la noción de utopía relacionada con la de historia en Respiración artificial de Ricardo Piglia. En tanto la utopía es usualmente comprendida como un sin-lugar, Piglia, nos sugiere un emplazamiento de extrañeza y añoranza gracias a que él elabora un discurso sobre la naturaleza de la novela y de su lector futuro; ello mediante un juego narrativo y reflexivo en el que la trama inscribe a un personaje que escribe a un tiempo futuro, al igual que pretende reescribir la historia. Lo utópico pareciera estar proyectado a otro tiempo, aunque pronto constatamos que tal proyección implica un bloqueo. Así, en el artículo se discuten las dimensiones que supone la idea de historia, como trama y como escritura de futuro, con su propio lenguaje y sus propias determinaciones internas. Tal idea de historia encuentra su limitación con el horizonte de futuro donde se recepta la comunicación de la escritura.
\end{abstract}

Palabras clave: Ricardo Piglia; Historia; Utopía; Dictadura; Futuro

\begin{abstract}
The article examines the notion of utopia related to history in Ricardo Piglia's Respiración artificial. While utopia is usually understood as placeless, Piglia suggests a place of strangeness and nostalgia because he makes a discourse on the nature of the novel and its future reader, through a narrative and reflective game in which the plot is about a character who writes to a future time, just as he intends to rewrite history. The utopian fact seems to be projected to another time, although soon we verify that such a projection implies a block. Thus, in the article the dimensions of the idea of history are discussed, as a plot and as a writing of the future, with its own language and its own internal determinations. Such idea of history finds its limitation with the horizon of the future where the communication of writing is received.
\end{abstract}

Keywords: Ricardo Piglia; History; Utopia; Dictatorship; Future

Recibido: 19.12 .19

Aceptado: $22.02 .20 \mathrm{~s}$ 


\section{Introducción}

“¿Hay una historia?” Así inicia Piglia Respiración artificial (2010, p. 13). Estamos en el espacio de la novela donde se cuenta una historia, pero también nos hallamos ante un momento imaginario, un presente, desde el que se ve la historia de Argentina. El asunto está en que el autor, al usar la ficción, al aludir a períodos históricos y al situarnos en el pasado desde el presente, además nos hace pensar en la historia como pretensión de futuro, como escritura utópica.

El ficticio traidor del presidente Juan Manuel Rosas, Enrique Ossorio — en el exilio, en efecto-, señala su deseo de escribir una utopía donde dirá lo que imagina será el porvenir de la nación argentina; piensa que él es "todos los nombres de la historia” (Piglia, 2010, p. 69), y su misión es poner por escrito las/ sus vivencias de político proyectadas en un tiempo hipotético. Menciona: "yo escribiré sobre el futuro porque no quiero recordar el pasado. Uno piensa en lo que vendrá cuando se dice: ¿Cómo puede ser que no haya podido ver entonces lo que ahora parece tan evidente?” (Piglia, 2010, p. 70).

¿Se puede escribir la historia del futuro o es la historia una escritura del futuro? ¿Es el pasado el futuro del presente? Cabe discutir estas preguntas alrededor de la novela de Piglia, sugerente en todo sentido.

\section{Los trazados de la novela}

Con el profesor Marcelo Maggi, uno de los personajes de Respiración artificial, entramos en el campo de la historia. Como historiador intenta analizar ciertos documentos escritos hace cien años por Enrique Ossorio, los cuales se plantean imaginar el futuro, desde el momento de su escritura, la Argentina cien años después. Aunque resulte paradójico, este hecho pone en diálogo dos contextos: la dictadura de Rosas, en el siglo XIX, con la de los militares, en el XX. Se trataría de "reconstruir a futuro (el de toda voluntad intelectual) un pasado en que se construía un futuro que era ya presente" (Gómez, 2007, p. 98).

Así, Ossorio escribe unas cartas en las que bosqueja su intención de hacer historia en tono prospectivo. Las cartas guardadas en un cofre son obtenidas por Luciano Ossorio, su heredero y además político en la Argentina de comienzos del siglo XX. Maggi se interesa por escribir la biografía de Enrique Ossorio y el cofre 
de quien fuera su nieto es la parte fundamental de todo su trabajo. Pero también está su dilema: “Cómo narrar los hechos reales?” (Piglia, 2010, p. 19). Si se escribe la historia para el futuro, si se escribe la historia del futuro, si se escribe la historia pasada en tiempo futuro, ¿es posible narrar hechos reales? Dejemos la respuesta para más adelante. En todo caso, como punto de partida, centrémonos en los itinerarios que tiene la novela Respiración artificial con relación a la idea de historia y la utopía.

El primer itinerario se relaciona con esa especie de diario/cartas en tono autobiográfico que escribe Ossorio. En principio, es lo epistolar la forma narrativa de la historia. Se trata de cartas para que alguien las lea en el futuro. Esto remite al hecho de que, entre la escritura y la lectura, hay un arco temporal donde prevalece un texto, un tejido de sentido cifrado para ser interpretado. La escritura, en este caso, como dice Fogagnoli, es un hecho privado, íntimo, "en [el] que la lengua abandona el rigor que se le suele otorgar en tanto que palabra escrita, deslizándose, en cambio, hacia la coloquialidad de un diálogo en viva voz [mediante una especie de] desordenada secuencia de textos" (2012, p. 55).

Es el narrador el que cuenta algo, pero, al mismo tiempo, pretende ser autor de una obra inédita; supone así, parafraseando a Barthes, un texto vacío, que está codificado, y un texto expresivo que intenta significar algo (2004, p. 51). El juego implica un extrañamiento entre la realidad contada, lo vivido, y el deseo de poder ser dilucidado cuando la historia, a través de la carta, sea decodificada. Empero, hay, por contraposición, otro juego más, un procedimiento: el narrador/ autor escribe también las misivas a partir de "recibir" cartas del futuro, desde 1979. Lo que hay en este juego de procedimientos, para narrar la historia, es lo que Piglia (en boca de Ossorio) dice de lo epistolar, del intercambio de cartas, como el lugar, o con más propiedad, como la forma de la utopía:

La correspondencia en sí misma ya es una forma de la utopía. Escribir una carta es enviar un mensaje al futuro; hablar desde el presente con un destinatario que no está ahí, del que no se sabe cómo ha de estar (en qué ánimo, con quién) mientras le escribimos y, sobre todo, después: al leernos. La correspondencia es una forma utópica de la conversación porque anula el presente y hace del futuro el único lugar posible del diálogo. (2010, pp. 84-85) 
Mientras el uno escribe $s u$ versión de la historia para alguien ignoto, el otro, desde casi finales del siglo XX, habla de la historia. Y esto parece darse en concreto en la segunda parte de la novela, cuyo contenido se relaciona indirectamente con la primera. Esta se denomina "Si yo mismo fuera el invierno sombrío", mientras la segunda se intitula "Descartes". En la primera está la historia familiar ligada a la historia del país a través de Ossorio, mientras en la otra parte prevalece una extensa discusión que liga la literatura, la historia y la sociología; los hilos temáticos desmenuzados allá tienen relación con aspectos inherentes a la primera parte, aunque el título "Descartes" suponga la idea de los descartes que un autor haría de lo que ya fue escrito En sentido general, se trata de lograr correspondencia, es decir, comunicación entre dos momentos de la historia argentina. Así, pretender comunicación es buscar ser correspondido.

¿Quién habla en el futuro-presente?: Emilio Renzi, un escritor (el alter ego de Piglia, siendo además historiador), el cual debe continuar la obra de su tío Maggi. Este quiere legar a Renzi lo que ha estado escribiendo sobre Ossorio. Se infiere que Renzi vive en el momento en que Argentina está bajo una dictadura militar, la de la década de 1970. Entre Maggi y Renzi hay ciertamente un intercambio epistolar. Piglia usa esta relación íntima, personal y familiar para instituir una línea de continuidad con el fin de que no se rompa lo que se pretende "historiar", cuestión iniciada por Ossorio en el siglo XIX. Echavarren sugiere que tal estrategia narrativa implica la herencia de pensamiento a partir del traspaso de documentos, estableciéndose así una "paternidad" de ideas que debe ser continuada:

Los lectores de [los papeles de Ossorio] (su nieto el ex-Senador, el yerno de este, Maggi, y el sobrino de Maggi, Renzi) están escalonados en sucesivas generaciones de argentinos. Forman una cadena ligada no solo por el parentesco de sangre o político, sino por el legado de una vocación de pensamiento. Ninguno de ellos es el padre carnal del otro, pero cada uno de ellos oficia de padre simbólico de su sucesor. Junto con los documentos de Ossorio se transmite la responsabilidad de pensar el destino histórico argentino, que es, por lo demás, el propio. El diálogo entre ellos no es directo. A través del protocolo, o colación de escritos [...] se establece un sistema de relevo. El sucesor hereda, se hace cargo, no solo de los documentos que han llegado hasta él, sino de una tradición de pensamiento que debe llevar adelante. (1983, p. 999) 
En este marco, la comunicación quiere ser continua, desde el pasado al futuro, como un relato que se sigue escribiendo, pero también en modo inverso, desde el presente (futuro) hacia el pasado para interrogar acerca de la utopía pensada y posiblemente no realizada.

Las cartas que se escriben en ambos sentidos son para hablar de algo que se hereda y algo que se evalúa de tal herencia. Echavarren señala: "La sucesión no pasa de padre a hijo según el registro civil, sino de abuelo [Enrique] a nieto [Luciano], de suegro [Luciano] a yerno [Maggi], de tío [Maggi] a sobrino [Renzi]. Se trata de una paternidad mediata, lateral, desviada, adoptiva, e implica el consenso" (1983, p. 999). Los personajes están emparentados, ligados, por la historia.

Las misivas que se intercambian en la novela, de hecho, son familiares y coloquiales. Las cartas quieren ser el punto de encuentro hipotético de una comunicación histórica con base en un proyecto en ciernes. Derrida escribe, aludiendo a una hipotética correspondencia utópica, pero además imposible, entre Sócrates y Freud lo siguiente:

¿Quién escribe [finalmente]? ¿A quién? ¿Y para enviar, destinar, expedir qué? ¿A qué dirección? [...] no lo sé. [...]. Que los firmantes y destinatarios no siempre sean visibles y necesariamente idénticos de un envío al otro, que los firmantes no se confundan necesariamente con los remitentes ni los destinatarios con los receptores, ni siquiera con los lectores $[\ldots]$ ya lo experimentarán ustedes y lo sentirán a veces con gran viveza, aunque de manera confusa. (2001, p. 15)

Esta descripción se puede parangonar con el proceso comunicativo, con el ir y venir, con el flujo de cartas, particularmente con la construcción de la idea de historia alrededor de un asunto latente en el libro de Piglia. Pensando en los planteamientos de Echavarren, ¿la novela no sería el diálogo entre el pensador rosista y el escritor del siglo XX acerca de la utopía en relación con la idea de "patria"? Entonces, el segundo itinerario es el de la comunicación entre dos tiempos, el de la correspondencia entre dos historias que, al mismo tiempo, es una sola, con una escritura, la de la utopía en referencia con la patria.

\section{El argumento de la utopía (histórica)}

Escribir una utopía, ese es el propósito explícito dentro del relato en la primera 
parte de Respiración artificial. Habría tres argumentos que justifican tal escritura: a) aliviarse de una pesadilla, b) el exilio como utopía, y c) la utopía como imaginación del futuro.

Maggi señala en la posdata de una carta: "La historia es el único lugar donde consigo aliviarme de esta pesadilla de la que trato de despertar" (Piglia, 2010, p. 19). Indicamos que él es heredero de una historia familiar que también tiene lazos con la historia de Argentina (se declara radical sabattinista, es un caballero irlandés, tiene el segundo apellido de un almirante, Pophan); el pasado de pesadilla supone el mundo de los fracasos. Maggi escribe: "Hay que hacer la historia de las derrotas. Nadie debe mentir en el momento de la muerte" (Piglia, 2010, p. 17). Ossorio, por su parte, se plantea escribir una utopía para no "recordar el pasado" en alusión a su fracaso político en la administración de Rosas (Piglia, 2010, p. 70). Piglia sugiere, mediante estas menciones, que la escritura de la historia supone un salto que, partiendo de pensar lo pasado, implica más bien reflexionar los proyectos políticos y sus alcances; en tal sentido, la historia se relacionaría más bien con la utopía. Así, quien escribe imagina el futuro como un medio para confrontar su experiencia, pero también para pensar lo que podría ser, aunque en principio esto suene fantasioso.

¿Cuál es la experiencia que obliga a pensar el futuro? La escritura de la utopía es el medio para superar el trauma, y es entendida más bien como una “distopía del espíritu” (Roth, 2007, p. 233), una dislocación, una separación producida luego de la opresión. Puesto que se nos sitúa en el emplazamiento de la novela como utopía posible, la escritura, dice Piglia, "es un lugar donde los borradores de la vida son posibles" (2001, p. 109). Para él, vivir es siempre un borrador susceptible por mejorar y ser transformado. Cuando se ha vivido algo (el mundo de la experiencia), uno se da cuenta recién de lo que pudo haber hecho en función de los sucesos. Escribir es, por lo tanto, el camino de reubicación y una hermenéutica, incluso en el sentido que da Foucault: el medio de autoexamen con relación a la experiencia vital con la realidad (2000b, p. 78).

La idea de que Ossorio formó parte del gobierno de Rosas nos lleva a un momento de la historia argentina problemática, signada por la dictadura. Ossorio quiere hablar de ello, pero, al mismo tiempo, ver el corolario de tal lapso 
histórico. Cuando decide escribir su utopía elige, digamos así, la forma de la novela, para "historiar" o para hacer esa hermenéutica:

El tiempo 'real' de la novela irá desde marzo de 1837 a junio de 1838 (Bloqueo francés, Terror). Durante ese lapso, por medio de un procedimiento que debo resolver, el protagonista encuentra (tiene en su poder) documentos escritos en la Argentina en 1979. Reconstruye (imagina), al leer, cómo será esa época futura. (Piglia, 2010, p. 84)

Es importante darse cuenta de que, si bien su recurso narrativo serán las cartas (el medio), el modo de agruparlas (intentado disponerlas como si se quisiese ordenar las ideas sobre la historia) y de hacer que ellas digan algo acerca de la utopía que se plantea escribir, conduce a que estemos frente a un ensayonovela, con la forma de la novela (el canal). En las cartas estaría la "historia" como mensaje, pero el vehículo para contarla sería el de la novela como tal. White señala que el historiador puede explicar los hechos ya sea: a) construyendo un relato (una trama), b) argumentando, o c) teniendo una posición ideológica. De acuerdo con ello, en el caso del relato, donde se encontraría la forma de la novela, la "historia" se trama de cierto modo (White, 1973, p. 8); en la novela (romance philosophique) habría un drama de autoidentificación y un héroe que triunfa sobre el mal (White, 1973, p. 148). Teniendo en cuenta lo que señala Aínsa, pienso, entonces, que Piglia estaría confrontando, y, al mismo tiempo, poniendo en diálogo, la historia, como una narración de los hechos, con la ficción, como el lugar en donde se crea una realidad alternativa (Aínsa, 2003, p. 19), el emplazamiento de la utopía. Si se consideran los planteamientos de White, es obvio pensar que Piglia juega entre la construcción de un relato donde aparece otra novela, la que escribirá Ossorio, del mismo modo que adopta una posición (Respiración artificial, así, es un pretexto).

La escritura de la utopía entonces se articula porque hay una experiencia previa que, en este caso, está señalada por las palabras "bloqueo francés" y "terror", en alusión a dos hechos que evidenciaron los problemas de gobernabilidad de Rosas: el uno, asociado al intercambio comercial económico internacional y, el otro, a las persecuciones realizadas contra opositores al régimen, cuestiones que reflejarían la falta de libertades. Estos dos aspectos parecen definir, asimismo, al gobierno de Rosas como el de la barbarie política. Empero en Piglia tal situación 
se encuentra ligada a otro problema: que en la Argentina del siglo XIX las clases sociales oligárquicas apoyaban las invasiones extranjeras (como la de Pophan y el bloqueo francés); además, añoraban una cultura "francesa" o "europea", frente a la prevaleciente, la cual era barbárica y abyecta (Piglia, 2010, pp. 130-131). Este asunto, que podría tener aún cierta vigencia, puede llevar a que nos planteemos la pregunta: ¿Si hubieran triunfado tales invasiones, el destino de Argentina sería otro? O, mejor dicho: ¿El ser nacional de Argentina se erige, en efecto, gracias a la cantidad de exiliados, deportados, refugiados de otros países? Ossorio vendría a encarnar el personaje de una generación que, amén de denunciar una dictadura, pretende luchar contra cierto imaginario extranjerizante (aunque, al mismo tiempo, conoce que no puede renunciar al legado extranjero) y fundar una real cultura nacional: "Ossorio participa, con el resto de la generación romántica, en la fundación de los principios y razones de eso que llamamos cultura nacional" (Piglia, 2010, p. 31). ¿Esta es, en realidad, la utopía?

Y acá hallamos un nuevo sentido. El exilio vendría a ser el lugar para pensar la utopía, o bien, "es el lugar de la utopía" (Piglia, 2010, p. 78). El exilio como utopía misma implica, de este modo, el espacio para hacer la hermenéutica de sí y de la experiencia vivida. Foucault, cuando se refiere a las "tecnologías del yo", entre ellas las cartas y la escritura en el mundo griego, advierte que, quien escribe, hace una narración de sus acciones y de su experiencia cotidiana (2000b, p. 63). ¿Acaso no vemos eso en Ossorio, quien "nos escribe" para contarnos lo que hará y cuál será el artilugio que usará para conseguir relatar la historia? Así, Ossorio dice:

El destierro, el éxodo, un espacio suspendido en el tiempo, entre dos tiempos. Tenemos los recuerdos que nos han quedado del país y después imaginamos cómo será (cómo va a ser) el país cuando volvamos a él. Ese tiempo muerto, entre el pasado y el futuro, es la utopía para mí. Entonces: el exilio es la utopía. (Piglia, 2010, p. 78)

Según lo anotado, es posible pensar la posibilidad de la utopía cuando uno ha sido degradado o ha sido echado, pero más todavía cuando ha vivido una época de terror y queda todo ello como un trauma. Solo se adquiere la conciencia de lo que pudo ser y lo que podría ser cuando se está fuera del poder o de un espacio de representación problemática: la utopía y el trauma se volverían, así, 
fenómenos irrepresentables, por lo que su explicitación vendría a ser "intensa" (Roth, 2007, p. 233), necesaria, fronteriza, puerta para resituar la historia. Y acá habría que hacer una primera aproximación a la noción de historia.

Foucault plantea que la historia es un tipo de discurso y, como tal, una forma de "correlato indispensable en la función fundadora del sujeto" (2003, p. 20). Siendo "correlato" estaría relacionado con otras construcciones de verdad que, en nuestro caso, también son relatos que ayudan a legitimar los acontecimientos y los que dotarían de consistencia a la experiencia. La historia, en tal caso, no tiene que ver con la totalidad, sino con el evento, con el acontecimiento. Aunque Foucault postule que el objeto de la historia — entendida esta primeramente en su obra como "genealogía"-, es lograr que los documentos se constituyan en monumentos, se puede afirmar con relación a la novela que analizamos y el tema de la escritura de la utopía, que la historia vendría a ser el correlato que pretende armar Ossorio, donde se explica sobre qué base se ha constituido la Argentina de cien años después; de esta manera, la historia sirve para reconocerse, incluso considerando los acontecimientos pasados, en cierto sentido, para lograr la reconciliación (Foucault, 2000a, p. 43).

Empero, ¿quién se reconoce? Ossorio, el cual aglutina a todos los nombres de la historia, es el primero que se reconoce en tal historia; pues él es, al mismo tiempo, uno de sus intelectuales que, en alusión al grupo de argentinos utopistas del siglo XIX, el de la Asociación de la Joven Generación Argentina, exiliados o desterrados en el período de Rosas, piensa una utopía para su país. Es el "traidor" de un régimen convertido en héroe; él es quien se figura como utopista:

\begin{abstract}
¿Qué lecciones he sacado de esa otra experiencia vivida por mí en el mundo alucinante de la utopía? [...] Solo en la mente de los traidores y de los viles, de los hombres como yo, pueden surgir los bellos sueños que llamamos utopías. [...] El traidor ocupa la posición clásica del héroe utópico: hombre de ningún lugar, el traidor vive entre dos lealtades; vive en el doble sentido, en el disfraz. Debe fingir, permanecer en la tierra baldía de la perfidia, sostenido por los sueños imposibles de un futuro donde sus vilezas serán, por fin, recompensadas. (Piglia, 2010, p. 79)
\end{abstract}

Lo que se postula es que la lejanía, el exilio, hace soñar y fabular. Pero también que el traidor transpone la frontera y, desde allá, fantasea con una nueva realidad, con el país utópico. En esta dimensión, el traidor pareciera un conspi- 
rador; mas viéndolo como héroe, es un transgresor que busca la redención. Cabe considerar que la palabra "traidor" tiene su raíz en el término latino traditio, el cual, en cierto sentido, implica "alguien que entrega". Podemos leer entonces la posibilidad de algo que se lega: Ossorio pretende, mediante su pensamiento, transmitir las ideas de una patria posible. Demaría, en alusión a la autobiografía de Juan Bautista Alberdi, Mi vida privada [1873], señala que el verdadero traidor fue Rosas, aunque este calificase de traidores a quienes eran críticos a su gobierno (1999, pp. 99-97): el traidor Ossorio, por lo tanto, transmite, si se quiere, la tradición de disentir y, con ello pensar algo nuevo y diferente.

La utopía se esboza como ese otro sentido que podría tener la vida social y política: es el espacio de la disidencia, es la esfera de la creación, es la instancia donde alguien que ha vivido de cerca la política ahora la repiensa; es el caso de Juan Bautista Alberdi, que en la novela vendría a ser Enrique Ossorio. Ahora veamos cómo se idea ese espacio:

La utopía de un soñador moderno debe diferenciarse de las reglas clásicas del género en un punto esencial: negarse a reconstruir un espacio inexistente. Entonces, diferencia clave: no situar la utopía en un lugar imaginario, desconocido (el caso más común: una isla). Darse en cambio cita con el propio país, en una fecha (1979) que está, sí, en una lejanía fantástica. No hay tal lugar: en el tiempo. Aún no hay tal lugar. Esto equivale para mí al punto de vista utópico. Imaginar la Argentina tal cual va a ser dentro de 130 años: ejercicio cotidiano de nostalgia, roman philosophique. (Piglia, 2010, p. 80)

Ossorio titula su novela: 1979. A diferencia de la idea generalizada de la utopía como "lugar" inexistente, en la novela más bien este es un momento imaginario (año 1979) en un determinado lugar (Argentina). Se estaría sugiriendo que aún no hay un emplazamiento, lo que lleva a pensar que este podría también construirse. Imaginar es, de este modo, hacerse una representación de algo que podría ser. Y en esa posibilidad está todo un nuevo juego de significados: pues la utopía no alude a isla alguna, sino a la Argentina futura (por ello Ossorio dice: "no situar la utopía en un lugar imaginario, desconocido", donde "desconocido" más bien implica lo contrario, tomando en cuenta el sentido de la frase). La utopía es la ficción de un modelo político; la utopía es imaginar, pero al mismo tiempo, al hacerlo, tomar en cuenta el hecho nostálgico. 
Para comprender toda esta red de significados vale la pena también tomar en cuenta una carta previa a la declaración de "escribir" 1979, en la posdata que dice: “A veces (no es joda) pienso que somos la Generación del 37. Perdidos en la diáspora. ¿Quién de nosotros escribirá el Facundo? (Piglia, 2010, p. 78). Esta posdata más bien "aparece" en una carta actual que es leída por el censor militar Arocena. Quien escribe se asimila como si fuera alguien de 1837 y sugiere volver a escribir el Facundo.

\section{Pensar la utopía desde el lugar excéntrico}

Piglia se sirve de Respiración artificial para hablar de la realidad política argentina, no solo contemporánea (el período de la dictadura militar del último tercio del siglo XX), sino desde que su país se constituyó en república. La cuestión de fondo tampoco son las propias dictaduras; al contrario, como se insinuó antes, es lo relacionado con la identidad nacional, con la idea de nación, de patria y de la propia historia argentina.

La novela es una extensa metáfora para discutir los anteriores aspectos. Quien habla desde el "nosotros" que escribirá el Facundo está aludiendo, en efecto, al movimiento fundante, si se quiere, de la identidad y de la nación argentina. Precisamos que Ossorio es la imagen o la representación de Alberdi y este, asimismo, fue parte de la generación de 1837 que debatía ideas políticas en el Salón Literario de Buenos Aires que luego se convertirá en la Asociación de la Joven Generación Argentina, junto a Domingo Faustino Sarmiento, Esteban Echeverría, Miguel Cané, entre otros. Tal salón era un movimiento intelectual romántico que postulaba la necesidad de llevar más allá la revolución independentista de mayo, cuestión que no se estaba realizando del todo con el gobierno de Rosas.

Ossorio en el exilio se piensa como parte de dicha generación; su lugar de enunciación es excéntrico. En la realidad, Rosas desarticuló el salón y logró que sus participantes vayan al exilio o sean desterrados. Demaría plantea que

Respiración artificial comienza exactamente donde termina El matadero de Esteban Echeverría: narra el "después" de la violencia al explorar el vacío dejado por la "desaparición" física de Marcelo Maggi. Cuento y novela inscriben como origen de la palabra un acto violento. $(1999$, p. 81) 
En otras palabras, la dictadura de Rosas (1829-1852) y la de los militares (1976-1983) se fundan en la intolerancia, la persecución y la opresión; la violencia del poder, a la final, se visibiliza ya sea en los perseguidos y exiliados o en la desaparición forzada de personas. Demaría llama la atención justamente sobre esto último: Maggi nunca llega a encontrarse con su sobrino Renzi; sus cartas son interceptadas por un censor. En el caso de Ossorio, él se exilia, pero luego se suicidará. En ambos casos, la premisa es reflexionar desde afuera el destino de la nación argentina.

Resaltemos que en la novela prevalecen dos referencias histórico-ficticias. Está la sombra de Alberdi, por un lado, y la de Sarmiento, por el otro. Sabemos que Alberdi fue un intelectual de profundas convicciones políticas. En principio, formó parte del Salón Literario de Buenos Aires junto a diversos intelectuales de su época. Este salón fue clausurado por el gobierno de Rosas. En 1837, Alberdi con Echeverría y otros fundaron la Asociación de la Joven Generación Argentina que luego será conocida como la Generación del 37. Rosas, intolerante con este grupo crítico, llevó a que sus integrantes sean perseguidos. Alberdi se exilió en Montevideo y desde allá continuó con su obra crítica al régimen. Tras un periplo por París, luego se encontró con otro miembro del grupo también exiliado, Sarmiento, el cual en ese momento estaba en Chile. A raíz de la derrota de Rosas en 1852, en una batalla contra Juan José Urquiza, a la que se unió Sarmiento como jefe militar, Alberdi, desde Chile envió a Urquiza un texto fundamental: Bases y Puntos de Partida para la Organización Política de la República Argentina [1852], donde se planteaban los criterios esenciales que permitieron la reescritura de la Constitución Argentina de 1853. Su trabajo se inspiraba en los ideales liberales.

De acuerdo con lo anterior, como Alberdi, otros intelectuales de la Generación del 37 tomaron partido por el cambio, aunque después se enrumbaron hacia diferentes destinos a mediados del siglo XIX. Si las ideas de Alberdi fueron esenciales para el cambio de la Constitución política, las de Sarmiento fueron a la par vitales para Argentina. De hecho, Domingo Faustino Sarmiento luego se convirtió en presidente (lo mismo que Bartolomé Mitre, otro de los miembros del grupo). Sarmiento era un intelectual con vocación de educador; conformó la 
Sociedad Literaria que luego pasó a ser la Asociación de Mayo, también en contacto con la Sociedad de Alberdi. Exiliado en Chile, abrazó la causa militar contra Rosas. Su obra cardinal fue Facundo [1845], retrato del caudillo Juan Facundo Quiroga. Este libro - que puede verse como un ensayo híbrido- pretende ser un acercamiento sociológico a la identidad argentina basada en el conflicto "civilización" y "barbarie". Lo mismo que en Alberdi, su inspiración era romántica y liberal.

Alberdi y Sarmiento, como muchos de los intelectuales de la Generación del 37, eran utopistas. Todos ellos creían en ideales nuevos y, es por ello, que luego casi todos ocuparon diferentes planos de la vida política tras la caída de Rosas. Esteban Echeverría será quien, por ejemplo, escribirá los ideales que perseguía toda esta generación. En su texto Código o declaración de los principios que constituyen la creencia social de la República Argentina [1839], reescrito como Creencia social [1841] están inscritos los conceptos que señalan los postulados ideológicos del grupo. Dicho manifiesto aparece reproducido en el capítulo "Presente y porvenir" del Facundo (Sarmiento, 2011, p. 345).

De acuerdo con Abramson, aquel manifiesto era un

[...] programa de acción de un grupo que quiere ser el fermento de una nueva sociedad en América, el cual está abundantemente inspirado en el de la Joven Europa. La palabra clave de este es sociabilidad, empleada en el sentido específicamente americano de "cimiento para construir una nación". (1999, p. 110)

La utopía que se idea en este grupo supone el progreso del país abriendo las puertas de Argentina a quienes puedan contribuir con su engrandecimiento. No es extraño oír en Alberdi la máxima "Gobernar es poblar" (cit. por Abramson, 1999, p. 110), del mismo modo que en la "Introducción" de Facundo, donde se postula que:

¿Hemos de cerrar voluntariamente la puerta a la inmigración europea que llama con golpes repetidos para poblar nuestros desiertos, y hacernos, a la sombra de nuestro pabellón, pueblo innumerable como las arenas del mar? ¿Hemos de dejar, ilusorios y vanos, los sueños de desenvolvimiento, de poder y de gloria, con que nos han mecido desde la infancia, los pronósticos que con envidia nos dirigen los que en Europa estudian las necesidades de la humanidad? Después de la Europa, ¿hay otro mundo cristiano civilizable y desierto que la América? ¿Hay en la 
América muchos pueblos que estén, como el argentino, llamados, por lo pronto, a recibir la población europea que desborda como el líquido en un vaso? ¿No queréis, en fin, que vayamos a invocar la ciencia y la industria en nuestro auxilio, a llamarlas con todas nuestras fuerzas, para que vengan a sentarse en medio de nosotros, libre la una de toda traba puesta al pensamiento, segura la otra de toda violencia y de toda coacción? ¡Oh! ¡Este porvenir no se renuncia así no más! (2011, pp. 44-45)

La palabra "poblar" resuena con fuerza sugiriendo abrazar a las corrientes migratorias europeas; lo que Alberdi y Sarmiento parecen sugerir es que la tradición española es más bien causa para que se instaure la barbarie; frente a ello, se promete la civilización que más bien se desarrolla en Europa. En Respiración artificial, la referencia a dicha utopía está en esa carta interceptada por el censor Arocena. Quien escribe es una variedad de referencias; en todo caso se piensa allá en un mapa utópico de corte nacionalista:

[...] los argentinos "del exterior" [...] pongamos plata y nos compremos entre todos una isla en el Pacífico [...]. Plantaríamos trigo, criaríamos vacas, pero sin olvidar la protección de las artesanías del interior. Nos independizaríamos de la corona española, pero sin afrancesarnos. Nacionalizaremos las rentas de la Aduana y rechazaremos la enfiteusis de Rivadavia para cortar las raíces del latifundio. Mariano Moreno permanecerá en el país, al frente de la Junta Grande, sin viajar a Europa, cosa que no se nos muera en alta mar, etc. Sería, según él, la primera utopía nacionalista. (Piglia, 2010, p. 77).

Es obvia la ironía perfilada en esta cita: hay quienes pretenden fundar de nuevo la nación argentina y llevar el progreso a su más alto punto. En este contexto, Ossorio es menos pragmático y más bien más idealista: la utopía no supone lugar, sino momento. Se puede ver acá que hay dos tipos de utopías, la que postula Sarmiento y la de Alberdi. La novela de Piglia parece poner en conflicto este hecho.

\section{Utopía o desencanto de la utopía}

Luego de realizado el examen de los trazados de la novela de Piglia alrededor de la escritura de una utopía, pongamos en claro, sin embargo, dos asuntos: a) la "novela" de Ossorio implica la intención de narrar la utopía de la Generación del 37; y b) la novela de Piglia supone más bien no solo desentrañarla, sino poner en evidencia una falla. Acá estarían los dos aspectos señalados por White: a) usar una trama para relatar la historia (donde esta se constituye en discurso) y b) lograr un 
punto de vista (donde el discurso elaborado pretende criticar a la trama). Se puede ver acá un dispositivo que es recurrente en la literatura de Piglia: se trata de la dimensión de lo especular, en el sentido de su derivación de la idea de "espejo".

En la narración de la historia, en la pretensión de un discurso, el cual, al mismo tiempo, se le deconstruye usando la estrategia de la ficción, Piglia lleva a que nos interroguemos, como señala Sequera, sobre lo que es real y lo que es ficticio (2009, p. 87) de la historia y de la realidad argentina. En este juego, es claro el manejo de los tiempos, el uso de un lenguaje "circular", por el que se tensiona la idea de un solo presente, de un solo pasado, saltando a una multiplicidad de sentidos, gracias a los cuales, el autor sugiere que el lector no vea/lea el reflejo de la historia (la realidad), sino "el punto de partida para la construcción de lo real" (2009, p. 83). Y eso tiene que ver con las tesis de White respecto a la noción de identificación ideológica que se relaciona con la posición del historiador respecto a los acontecimientos:

[...] los historiadores tratan típicamente de determinar no solo "lo que ocurrió" sino el "significado" de ese acontecer, no únicamente para los agentes pasados de los acontecimientos históricos sino también para los subsecuentes [...]. La escritura histórica es un medio de producción de significado. (2003, p. 51)

Piglia quiere establecer no un significado, sino una convergencia de símbolos alrededor de la idea de historia. El efecto "caleidoscópico" del dispositivo de Piglia implica, entonces, una constante interrelación entre narración y tiempo (Sequera, 2009, p. 86), donde lo especular, que además pone en movimiento esa identificación ideológica, hace que siempre el lector se tensione en una especie de temporalidad-intemporalidad. Ello se refuerza con el arte narrativo declarado por Piglia en Respiración artificial: hacer una historia, pero a sabiendas que hay un lector del futuro, el cual, por otro lado, tendrá que hacer el acto de lectura como si estuviera además en el futuro mirando el pasado "histórico". Al respecto, Piglia sabe que esto se desprende del dispositivo señalado: "En el fondo los relatos sociales son alegóricos, siempre dicen otra cosa. Hablan de lo que está por venir, son un modo cifrado de anticipar el futuro y de construirlo" (2001, pp. 37-38).

De ahí que, en primera instancia, la utopía de Ossorio (Alberdi y además Sarmiento) y su estrategia de legarla hasta el año 1979 (desde donde recibirá, además, las cartas de respuesta) implica, a mi modo de ver, la discusión de lo que 
podría ser el futuro. Hay dos presupuestos que trazan el sentido de dicha utopía (como una historia escrita desde el interior de la novela): a) la nación argentina puede llegar a un momento de cambio gracias al progreso; b) la nación argentina puede llegar a un momento de estancamiento (es la metáfora que representa Ossorio como político paralítico) y que puede derivar en su catástrofe gracias a la barbarie de la dictadura militar. Entonces, se perfila la idea de "civilización" y "barbarie" en dicha utopía.

En cuanto al primer presupuesto, Ossorio, exiliado, se radica en Estados Unidos; vive la fiebre del oro, admira al liberalismo naciente. Ossorio-Alberdi lee la Constitución norteamericana; sabe que allá está la simiente del progreso. Demaría dice que Ossorio conoce la "utopía alquímica" norteamericana y establece correspondencia con la suya; por ello Alberdi pondrá en su Bases y Puntos de Partida para la Organización Política de la República Argentina [1852] la idea que también debe prevalecer en la Constitución argentina, esto es: romper con la institucionalidad caduca y hacer que la gente (como ejemplo, California) haga una constitución "llena de previsión, de buen sentido y de oportunidad", donde haya libertad, tolerancia y progreso, donde la riqueza natural sea la causa de la libertad y la civilización, donde haya goce de derechos, de prerrogativas y privilegios del ciudadano, etc. (Demaría, 1999, p. 102).

Entonces, si tales son los ideales, Ossorio-Alberdi pretende legar esto al futuro. De ahí que la herencia supusiera el traspaso de papeles y de misión desde Ossorio a Renzi, tal como se dijo antes. En realidad, en sentido inverso, tal estrategia implica el trazado de lo que supone pensar la "patria": Ossorio-Alberdi invitan a Renzi-los argentinos a repensar la patria. Jiménez, tomando en cuenta las tesis de Ernst Bloch, señala que la patria "no se encuentra en el origen, sino en un tiempo que no ha llegado a ser todavía, el porvenir" (1983, p. 180). Eso es lo que hace Ossorio-Alberdi; en su estrategia está la nostalgia — “ejercicio cotidiano de nostalgia" (Piglia, 2010, p. 80) —; la idea es desencadenar, al tono de Bloch, la nostalgia, al deseo de retornar a lo que se recuerda:

Pero ¿de qué retorno se trata? No es una vuelta al pasado, sino un "retorno al futuro", [de acuerdo con Bloch, es el retorno] "a una patria donde no se había estado nunca, pero que es, sin embargo, la patria" [...]. Es un retorno a lo desconocido. (Jiménez, 1983, p. 45) 
Patria es volver a algo que no se ha conocido aún. En la ficticia novela 1979 de Ossorio se sugiere eso, por algo Alberdi dará las ideas para escribir la Constitución argentina de 1853. La utopía nace de la crisis y es el soplo para volver a la identidad.

En cuanto al segundo presupuesto, en un momento Ossorio parece estar poco convencido de lo que podría ser el futuro. Escribe: "Pero ¿será así? Preveo: disensiones, divergencias, nuevas luchas. Interminablemente. Asesinatos, masacres, guerras fratricidas" (Piglia, 2010, p. 70). Aunque esta especie de oráculo se refiera a lo que puede ser la guerra de liberación contra Rosas, en el fondo es un pensamiento que anticipa la década de 1970; en este contexto, es posible “denunciar los futuros crímenes" (Demaría, 1999, p. 103). La prueba de ello es la “desaparición” de Maggi que se entrevé en la lectura de la novela de Piglia.

En segunda instancia, en cuanto a que el historiador-novelista Piglia toma posición respecto a la historia, cabe decir que, en efecto, hurga en el sentido de lo que está en juego en el Facundo, es decir, aunque dicho texto esté postulando una utopía, al mismo tiempo supone una ambigüedad que entra en contradicción con su propio postulado, el de "civilización" y "barbarie". Esta tensión de ideas la realiza a partir del devenir de la literatura argentina, donde, hurgando la tradición literaria, el canon, identifica a quienes se acercaron a la "barbarie", intentando comprenderla y superándola, tratando de recuperar la noción pastoral de ubicar a la patria verdadera, la "civilización", en ese mundo rural que se debe repoblar (Fogagnoli, 2012, p. 60). En la parte "Descartes", en Respiración artificial, de hecho se hace una intensa reflexión acerca de los tópicos que configuran la identidad argentina (los inmigrantes, su relación con Europa...), el lenguaje nacional, teniendo en cuenta la literatura, el nacionalismo (con una utopía situada en una isla...), etc. Ahí aparece un asunto que es de particular atención:

[Es la cuestión del] europeísmo [...] lo que empieza ya con la primera página del Facundo. La primera página del Facundo: texto fundador de la literatura argentina. ¿Qué hay ahí?, dice Renzi. Una frase en francés: así empieza. Como si dijéramos la literatura argentina se inicia con una frase escrita en francés: On ne tue point les idées (aprendida por todos nosotros en la escuela, ya traducida). ¿Cómo empieza Sarmiento el Facundo? Contando cómo en el momento de iniciar su exilio escribe en francés una consigna. El gesto político no está en el contenido 
de la frase, o no está solamente ahí. Está, sobre todo, en el hecho de escribirla en francés. Los bárbaros llegan, miran esas letras extranjeras escritas por Sarmiento, no las entienden: necesitan que venga alguien y se las traduzca. ¿Y entonces?, dijo Renzi. Está claro, dijo, que el corte entre civilización y barbarie pasa por ahí. Los bárbaros no saben leer en francés, mejor: son bárbaros porque no saben leer en francés. Y Sarmiento se los hace notar: por eso empieza el libro con esa anécdota, está clarísimo. Pero resulta que esa frase escrita por Sarmiento (Las ideas no se matan, en la escuela) y que ya es de él para nosotros, no es de él, es una cita. Sarmiento escribe entonces en francés una cita que atribuye a Fourtol, si bien Groussac se apresura, con la amabilidad que le conocemos, a hacer notar que Sarmiento se equivoca. La frase no es de Fourtol, es de Volney. O sea, dice Renzi, que la literatura argentina se inicia con una frase escrita en francés, que es una cita falsa, equivocada. Sarmiento cita mal. En el momento en que quiere exhibir y alardear con su manejo fluido de la cultura europea todo se le viene abajo, corroído por la incultura y la barbarie. A partir de ahí podríamos ver [...] cómo prolifera esa erudición ostentosa y fraudulenta, esa enciclopedia falsificada y bilingüe. Ahí está la primera de las líneas que constituyen la ficción de Borges: textos que son cadenas de citas fraguadas, apócrifas, falsas, desviadas; exhibición exasperada y paródica de una cultura de segunda mano, invadida toda ella por una pedantería patética: de eso se ríe Borges. (Piglia, 2010, pp. 130-131)

Pues bien, es el problema de la identidad lo que está de fondo. La historia de Argentina es, como en todos los países, la historia de sus acontecimientos vistos como conflictos. Argentina, tras la utopía de Alberdi-Sarmiento, se organiza sobre la base de lo extranjero, de eso que criticaban o, en cierto modo, rechazaban los ideólogos del 37 para postular una cultura verdaderamente nacional. Piglia hace ver que, al tratar de imitar a los franceses, se los cita mal, apareciendo una identidad que pretende ser erudita, ostentosa y pedante: en definitiva, la cultura parece traducir este problema. Si Borges es el otro extremo de Sarmiento, a su vez es quien, según Piglia, ironiza toda esta identidad siendo él el ejemplo de su burla. En dicho contexto, la escritura de la utopía es un modo de dejar en suspensión ese otro reconocimiento con la patria y la identidad nacional que parece estuvo en debate en la dictadura militar argentina de la década de 1970. En tal sentido, Piglia sostiene: "La utopía importa porque es la antirrealidad, porque es un modo de no aceptar el mundo tal cual es y aspirar a otra cosa" (2001, p. 133). ¿No es acaso el juego de relatos, de historias presentes en la novela de Piglia entonces una especie de discur- 
so (histórico) que pretende desnudar el origen y la actualidad de la argentinidad?

Para concluir diré, en función de las preguntas iniciales, que Piglia escribe una historia que quiere ser del futuro, con las estéticas de la novela histórica (ficcionalización de hechos), haciendo varias preguntas al pasado, y de la novela policial (investigación de un secreto y fabulación conjetural y especulativa), logrando que el lector se inquiete sobre la identidad. Desde este presupuesto cabe afirmar que la estrategia de relato, tal como se ha evidenciado en este ensayo, recurre a otra modalidad anclada en la exploración del lenguaje. Él postula que se ubica en el "relato futuro" en el que la utopía sería el de una lengua propia, una lengua generada por la novela (Piglia, 2015, p. 42), o un lenguaje que funda a la historia inscrita en la novela.

Piglia se plantea hacer de la historia como si fuera una escritura futura y/o una escritura del futuro: así el presente es la materia del futuro y, en igual medida, el pasado es la materia del presente. Si tomamos en cuenta lo que discutimos acerca de la noción de patria, es posible afirmar que la novela, aunque implique que en la década de 1970 Argentina sobrevivía bajo "respiración artificial", es una interrogación acerca de "la problemática de la historia argentina" (Piglia, 2001, p. 112): es la problemática de los perdedores que finalmente no pudieron concluir con sus visiones utópicas; así Sarmiento desconoce a Alberdi y, en cierto modo, desautoriza a la Generación del 37. Alberdi, por su lado, no puede concluir con sus postulados porque no domina la política; el primero es más político y el segundo, un intelectual. La "política militar", si cabe el término, lleva a que la utopía prevista en el siglo XIX tampoco se concrete. En síntesis, la pregunta sobre si hay una historia puede resolverse en el sentido de que no puede haber una historia, un gran relato, sino unas historias, como los relatos de quienes no han sido admitidos por la historia oficial.

Acá vale conectar la idea que Piglia sostiene respecto a que somos contadores de historias, narradores que cuentan experiencias y suscitan implicación del lector o del oyente. Lo que se narra hace aparecer lo que la historia borra; y cuando se resitúa esa memoria, se vuelve a conectar en el presente no solo el pa- 
sado, sino cómo los que vivieron, los que fueron testigos de los acontecimientos, alguna vez hicieron acciones que debían tener efecto en el futuro. Y no solo eso, hacer historia, además de volver a situar mediante la narración, es "cómo se ha construido cierta idea de identidad" (Piglia, 2007, párr. 18). Respiración artificial, novela-ensayo, historia anticipatoria, vendría a ser el relato-pregunta sobre la identidad, gracias a su modelo coloquial-reflexivo. Pero también vendría a ser el medio comunicativo para desatar diversas preguntas sobre la naturaleza de la ficción, de la historia como ficción.

\section{Notas}

1 Cabe indicar que Piglia señala que su aspiración era ser escritor, por lo que realizó estudios de Historia en La Plata: "pensaba (con razón) que si estudiaba Letras me iba a costar seguir interesado en literatura" (2001, p. 52).

2 Nombra a Amadeo Sabattini, político radical de la década de 1940 en Argentina, propulsor del industrialismo en la provincia de Córdova donde fue gobernador. Pretendía lograr una mejor distribución de las tierras.

3 La referencia es a Home Pophan, almirante inglés, el cual, hacia 1806, hizo una expedición para tomar la capital del virreinato de La Plata, hecho que se logró para beneplácito de ciertas familias que veían en la intervención militar británica la posibilidad de cambiar de destino y desembarazarse de la corona española.

4 Juan José Saer apunta este asunto en su diálogo con Piglia. Ahí recalca que este emplea el recurso que permite que la novela se transforme en una forma híbrida distinta a la escritura tradicional. Señala que esta modalidad es distinta a la "novela-tesis". Piglia (2015, pp. 23 y 24) responde que la intensión es la "tensión de ideas" que llevan a que las "ideas se ficcionalicen".

5 La diferencia entre medio y canal en el asunto que analizamos es el mismo que se usa en la teoría de la comunicación, es decir, en el caso del primero, como el sistema retórico que permite la transmisión de un mensaje y, en el segundo caso, como el recurso concreto, "físico", que hace posible tal transmisión (Fiske, 1984, p. 12).

6 En Respiración artificial, Ossorio habla de su novela como un romance philosophique. Para redundar más en nuestra argumentación, es también importante la "carta" del 24/7/1850 que escribe y donde se lee: “¿Por qué he podido descubrir que mi romance utópico tiene que ser un relato epistolar? Primero: la correspondencia en sí misma ya es una forma de la utopía. Escribir una carta es enviar un mensaje al futuro; hablar desde el presente con un destinatario que no está ahí, del que no se sabe cómo ha de estar (en qué ánimo, con quién) mientras le escribimos y, sobre todo, después: al leernos. La correspondencia es la forma utópica de la conversación porque anula el presente y hace del futuro el único lugar posible del diálogo. [...] Pero además existe una segunda razón. ¿Qué es el exilio sino una situación que nos obliga a sustituir con 
palabras escritas la relación entre los amigos más queridos, que están lejos, ausentes, diseminados cada uno en lugares y ciudades distintas? Y, además, ¿qué relación podemos mantener con el país que hemos perdido, el país que nos han obligado a abandonar, qué otra presencia de ese lugar ausente, sino el testimonio de su existencia que nos traen las cartas (esporádicas, elusivas, triviales) que nos llegan con noticias familiares?" (Piglia, 2010, p. 84).

7 Acá parece haber un guiño a la novela de George Orwell, 1984, obra que reflexiona hasta qué punto la dictadura del proletariado estalinista encuentra su límite cuando el poder domina todos los órdenes de la vida, crea fantasmagorías alrededor de un enemigo y lleva a inventar incluso la cotidianidad haciendo constantemente arreglos a la historia. Orwell, en su momento convencido socialista, tomó distancia para analizar el proyecto histórico en el que había participado. La novela es una distopía, pero con más propiedad, según Williams, es una putropía, una utopía traicionada y corrompida (1988, p. 357). Ossorio, en Respiración artificial de Piglia, pretendería, así, pensar cómo un régimen político traiciona sus ideales y lleva a la población a su propia sumisión.

8 Ossorio escribe su última carta que dice así: "Escuche Ud.: pues con la muerte en mí tengo experiencias. Camino odioso, peligrosísimo, el de la soledad. Para todos mis paisanos o compatriotas: Que yo no obrase en esta guerra sino por mi propia convicción. ¿Habremos de estar siempre alejados de la tierra natal? [...] No se desapasionen porque la pasión es el único vínculo que tenemos con la verdad. Respeten mis escritos, debidamente ordenados, a los que yo aquí nombro como sigue: mis Anales. ¿Quién va a escribir esta historia? Sea cual sea la vergüenza que me alcance no quiero yo renunciar ni a mi desesperación, ni a mi decencia. Me gusta y siempre me ha gustado su antefirma y permítame que la imite: "Patria y Libertad". Y he de tutearte, Juan Bautista, con tu permiso, por esta vez. Tuyo. Tu compadre, Enrique Ossorio, el que va a morir" (Piglia, 2010, pp. 31-32). Nótese en esta carta: a) parece una declaración de principios en donde se postula no renunciar a lo que se sueña; $b$ ) el autor nombra a Juan Bautista (Alberdi) para que recoja sus papeles y siga pensando la utopía; c) inscribe "patria y libertad".

9 De modo general, la estructura de Respiración artificial también es un homenaje al cuento de Jorge Luis Borges: "Tlön, Uqbar, Orbis Tertiu" [1940], cuyo argumento inicia con la mención a los espejos y, desde allá, la idea de un aparente doble que no es el mismo que su referente. De hecho, Borges es citado en Respiración artificial.

10 Incluso Piglia sugiere algo que es interesante respecto a la relación historia-literatura: "Un historiador es lo más parecido que conozco a un novelista. Los historiadores trabajan con el murmullo de la historia, sus materiales son un tejido de ficciones, de historias privadas, de relatos criminales, de estadísticas, y partes de victoria, de testamentos, de informes confidenciales, de cartas secretas, delaciones, documentos apócrifos. La historia es siempre apasionante para un escritor, no solo por los elementos anecdóticos, las historias que circulan, la lucha de interpretaciones, sino porque también se pueden encontrar multitud de formas narrativas y modos de narrar" (2001, p. 90). 


\section{Referencias bibliográficas}

Abramson, P. L. (1999). Las utopías sociales en América Latina en el siglo XIX (J. Padín Videla, Trad.). Ciudad de México: Fondo de Cultura Económica.

Aínsa, F. (2003). Reescribir el pasado: Historia y ficción en América Latina. Mérida: Centro de Estudios Latinoamericanos Rómulo Gallegos y Ediciones El otro, el mismo.

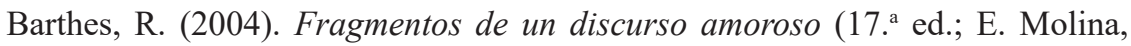
Trad.). Buenos Aires: Siglo XXI.

Demaría, L. B. (1999). Argentina-s: Ricardo Piglia dialoga con la generación del '37 en la discontinuidad. Buenos Aires: Corregidor.

Derrida, J. (2001). La tarjeta postal: De Sócrates a Freud y más allá (2. ${ }^{\mathrm{a}}$ ed.; H. Silva, Trad.). Ciudad de México: Siglo XXI.

Echavarren, R. (1983). La literariedad: "Respiración artificial", de Ricardo Piglia. Revista Iberoamericana, 49 (125), 997-1008. https://doi.org/10.5195/ REVIBEROAMER.1983.3854

Fiske, J. (1984). Introducción al estudio de la comunicación (P. Anzola, Trad.). Bogotá: Norma.

Fogagnoli, S. (2012). Nuevas lecturas de civilización y barbarie: La oralidad en la obra de Ricardo Piglia. Mitologías hoy, 5 (1), 52-61. https://doi.org/10.5565/ rev/mitologias. 15


Pérez, Trad.). Valencia: Pre-textos.

Foucault, M. (2000b). Tecnologías del yo y otros textos afines (M. Allendesalazar, Trad.). Barcelona: Paidós.

Foucault, M. (2003). Arqueología del saber (21. a ed.; A. Garzón del Camino, Trad.). Ciudad de México: Siglo XXI.

Gómez, A. (2007). Respiración artificial, novela ejemplar. En A. Gómez (Ed.), Provisoria-mente: Textos para Diamela Eltit (pp. 97-108). Buenos Aires: Beatriz Viterbo Editora.

Jiménez, J. (1983). La estética como utopía antropológica: Bloch y Marcuse. Madrid: Tecnos. 
Piglia, R. (2001). Crítica y ficción. Barcelona: Anagrama.

Piglia, R. (2007). El arte de narrar. Universum (Talca), 22 (1), 343-348. https:// doi.org/10.4067/S0718-23762007000100021

Piglia, R. (2010 [1980]). Respiración artificial (4. a ed.). Barcelona: Anagrama.

Piglia, R. (2015). Por un relato futuro: Conversaciones con Juan José Saer. Edición de P. Somoza. Barcelona: Anagrama.

Roth, M. S. (2007). Trauma: A Dystopia of the Spirit. En J. Rüsen, M. Fehr y T. Rieger (Eds.), Thinking Utopia: Steps Into Other Worlds (pp. 230-246). Nueva York: Berghahn Books.

Sarmiento, D. F. (2011). Facundo (5. ${ }^{\mathrm{a}}$ ed.). Madrid: Cátedra.

Sequera, M. (2009). Ricardo Piglia, el relato especular. Revista Letral, 3, 82-89. https://revistaseug.ugr.es/index.php/letral/article/view/3576

White, H. (1973). Metahistory: The historial imagination in nineteenth-century in Europe. Baltimore: John Hopkins University Press.

White, H. (2003). El texto histórico como artefacto literario (V. Tozzi y N. Lavagnino, Trads.). Barcelona: Paidós.

Williams, R. (1988). Science Fiction. Science Fiction Studies, 15 (46), 356-360. Recuperado de: https://www.jstor.org/stable/4239903 y http://www.depauw.edu/ sfs/documents/williams.htm. 